\title{
Successful treatment of tofacitinib in a case with rheumatoid arthritis who experienced hepatitis $B$ virus reactivation induced by tocilizumab and recovered from entecavir rescue therapy
}

\author{
Jin-Xian Huang (D), Li-Jun Zhang (1) \\ Department of Rheumatology, The University of Hong Kong-Shenzhen Hospital, Shenzhen, China
}

Biologics presenting with moderate risk for hepatitis $\mathrm{B}$ virus reactivation (HBV-R) were approved as alternative treatment for refractory rheumatoid arthritis (RA). ${ }^{1}$ In this article, we report a case with RA who recovered from tocilizumab (TCZ) induced HBV-R by entecavir (ETV) and was successfully treated with tofacitinib (TOF).

A 77-year-old male patient diagnosed with RA for three years had been followed at our department since March 2015. He had disease relapse despite methotrexate (MTX) and leflunomide (LEF) combination treatment. On admission, he had symmetrical joint swelling and tenderness of the shoulder, elbow, wrist, metacarpophalangeal joints, and knees. Laboratory results showed erythrocyte sedimentation rate (ESR) as $96 \mathrm{~mm} / \mathrm{h}$ C-reactive protein as $35.8 \mathrm{mg} / \mathrm{L}$ rheumatoid factor as $264 \mathrm{IU} / \mathrm{mL}$ and anti-cyclic citrullinated peptide antibody as $162.5 \mathrm{U} / \mathrm{mL}$. Serologies revealed hepatitis $\mathrm{B}$ surface antigen-positive, envelope antigen-positive and immunoglobulin (Ig) $\mathrm{G}$ antibody to hepatitis B core antigen-positive and envelope antibody-negative with a low titer of surface antibody of $1.38 \mathrm{mIU} / \mathrm{mL}$. Serum HBV deoxyribonucleic acid (DNA) was $2.04 \times 10^{3} \mathrm{IU} / \mathrm{mL}$. With high disease activity score DAS28, 6.8),
TCZ intravenous (8 mg/kg every four weeks) was started in May 2015. He experienced secondary loss of efficacy at the third infusion. ESR and interleukin-6 were extremely elevated while liver function was normal and HBV DNA remained at $8.23 \times 10^{3} \mathrm{IU} / \mathrm{mL}$. Treatment was changed to prednisone $15 \mathrm{mg} /$ day, celecoxib 0.2 twice a day combined with MTX $15 \mathrm{mg} /$ week and LEF $10 \mathrm{mg} /$ day. Ascending abnormal liver function was discovered with a peak alanine transaminase of $221 \mathrm{U} / \mathrm{L}$ and HBV DNA increased to $10^{7} \mathrm{IU} /$ $\mathrm{mL}$ after two months. Hepatic ultrasonography was normal. MTX and later on LEF were discontinued. HBV-R was confirmed and ETV $0.5 \mathrm{mg} /$ day was used. Viral load reduced to less than $5 \times 10^{2} \mathrm{IU} / \mathrm{mL}$ in three months and was undetectable in six months. Liver function returned to normal in nine months.

During the phase of HBV-R, the patient received methylprednisolone 6 to $8 \mathrm{mg} /$ day and hydroxychloroquine 0.2 grams twice a day. High-resolution computed tomography showed bilateral interstitial lung disease, thus tumor necrosis factor inhibitor was avoided. Iguratimod $25 \mathrm{mg}$ twice a day was initiated on July 2017 but failed to respond even with combination

Received: May 27, 2020 Accepted: July 22, 2020 Published online: December 14, 2020

Correspondence: Li-Jun Zhang, MD. Department of Rheumatology, The University of Hong Kong-Shenzhen Hospital, 518000 Shenzhen, China. Tel: +8618200983153 e-mail: zhanglj6@hku-szh.org tocilizumab and recovered from entecavir rescue therapy. Arch Rheumatol 2021;36(3):458-460. 


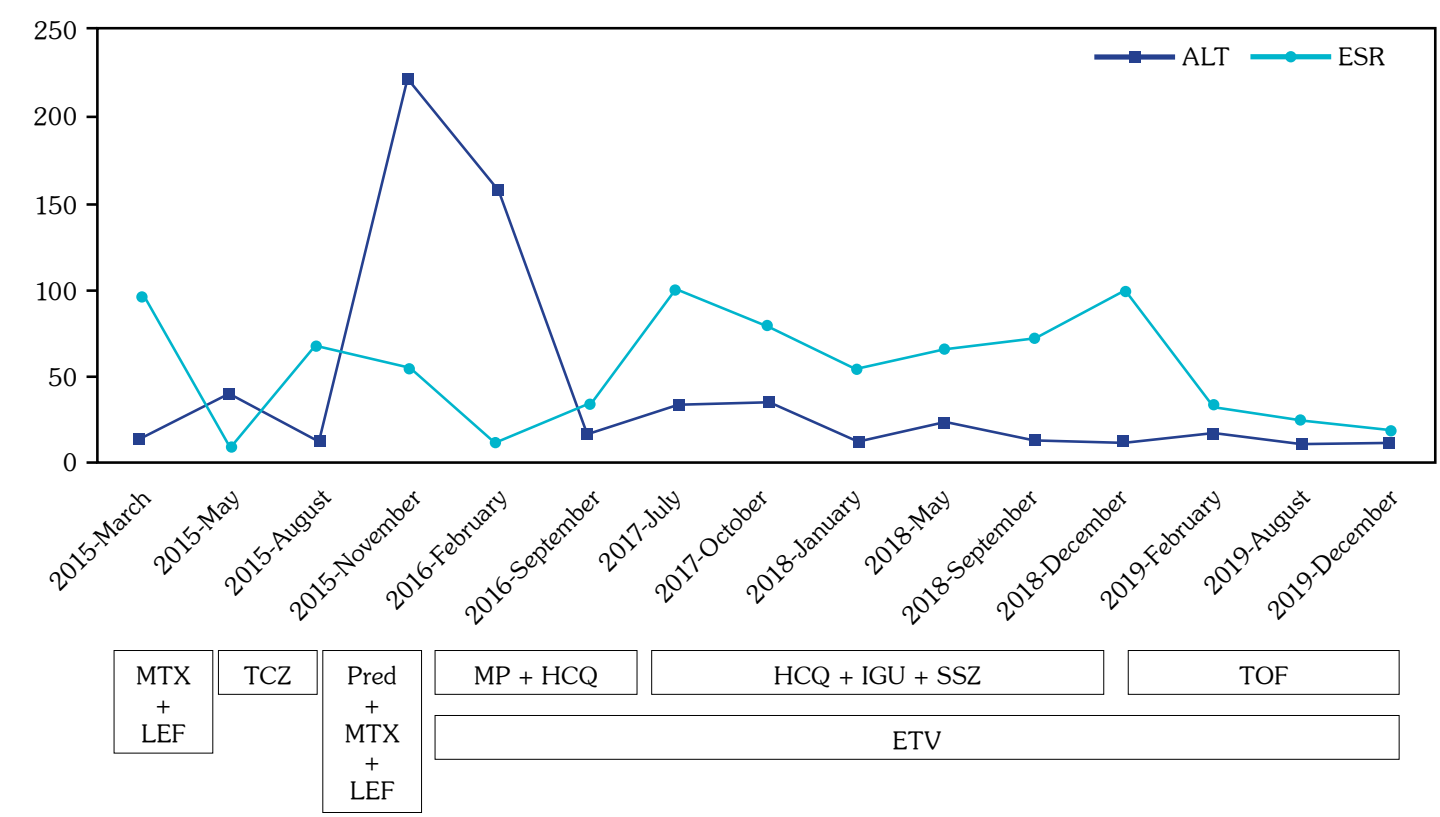

Figure 1. Flow chart of serological changes and treatment modification revealing an overview of changes in liver function, inflammatory markers and treatment.

ALT: Alanine transaminase; ESR: Erythrocyte sedimentation rate; MTX: Methotrexate; LEF: Leflunomide; TCZ: Tocilizumab; MP: Methlyprednisone; HCQ: Hydroxychloroquine; IGU: Iguratimod; SSZ: Sulfasalazine; TOF: Tofacitinib; ETV: Entecavir.

of sulfasalazine 0.75 twice a day. He required betamethasone injection during the subsequent 17 months. He agreed to commence with TOF 5 mg twice a day since December 2018. Repeated liver function and HBV DNA were normal. He responded well till the last visit on December 2019 (Figure 1).

Besides MTX and LEF, 2,3 TCZ was supposed to be a possible trigger for HBV-R. Luckily, rescue therapy prevented deleterious outcome. A case receiving TCZ for $>5$ years without hepatitis exacerbation was reported. ${ }^{4}$ However, TCZ without pre-emptive treatment can be fatal with fulminant hepatic failure. ${ }^{5}$ Prophylaxis is recommended with $\mathrm{HBV}$ infection in those receiving biologic disease-modifying anti-rheumatic drugs (bDMARDs). ${ }^{6}$ HBV-R risk is no greater with TOF than with bDMARDs. ${ }^{7}$ In a real world study in RA treated with TOF, half of HBV carriers experienced HBV-R but recovered after rescue nucleoside analogues. ${ }^{8}$ TOF therapy appeared to be effective and safe in HBV carriers with recovered HBV-R maintained on ETV treatment.

\section{Declaration of conflicting interests}

The authors declared no conflicts of interest with respect to the authorship and/or publication of this article.

\section{Funding}

The authors received no financial support for the research and/or authorship of this article.

\section{REFERENCES}

1. Choi J, Lim YS. Characteristics, Prevention, and Management of Hepatitis B Virus (HBV) Reactivation in HBV-Infected Patients Who Require Immunosuppressive Therapy. J Infect Dis 2017;216(Suppl_8):S778-S84.

2. Ming-Xu H, Chen M, Cai Y, Yan-Jia H. Clinical outcomes of low-dose leflunomide for rheumatoid arthritis complicated with Hepatitis B virus carriage and safety observation. Pak J Med Sci 2015;31:320-4.

3. Oshima $\mathrm{Y}$, Tsukamoto $\mathrm{H}$, Tojo A. Association of hepatitis $\mathrm{B}$ with antirheumatic drugs: a case-control study. Mod Rheumatol 2013;23:694-704.

4. Nagashima T, Minota S. Long-term tocilizumab therapy in a patient with rheumatoid arthritis and chronic hepatitis B. Rheumatology (Oxford) 2008;47:1838-40.

5. Sonneveld MJ, Murad SD, van der Eijk AA, de Man RA. Fulminant liver failure due to hepatitis $b$ reactivation during treatment with tocilizumab. ACG Case Rep J 2019;6:e00243.

6. Lau CS, Chia F, Dans L, Harrison A, 
Hsieh TY, Jain R, et al. 2018 update of the APLAR recommendations for treatment of rheumatoid arthritis. Int J Rheum Dis 2019;22:357-75.

7. Zhang Z, Deng W, Wu Q, Sun L. Tuberculosis, hepatitis $\mathrm{B}$ and herpes zoster in tofacitinib-treated patients with rheumatoid arthritis. Immunotherapy
2019;11:321-33.

8. Chen YM, Huang WN, Wu YD, Lin CT, Chen $\mathrm{YH}$, Chen DY, et al. Reactivation of hepatitis B virus infection in patients with rheumatoid arthritis receiving tofacitinib: a real-world study. Ann Rheum Dis 2018;77:780-2. 